\title{
The Persistence of Non-Vitamin K Antagonist Oral Anticoagulants in Korean Patients with Non- Valvular Atrial Fibrillation
}

Choong Sil Seong, MD; Hye Bin Gwag; Jin Kyung Hwang, MD; Seung Jung Park, MD; Kyoung-Min Park, MD; June Soo Kim, MD; Young Keun On, MD

Division of Cardiology, Department of Internal Medicine, Heart Vascular and Stroke Institute, Samsung Medical Center, Sungkyunkwan University School of Medicine, Seoul, Republic of Korea
Received: November 14, 2016

Revision Received: December 19, 2016

Accepted: December 23, 2016

Correspondence: Young Keun On, MD

Division of Cardiology, Department of Internal

Medicine, Heart Vascular Stroke Institute,

Samsung Medical Center, Sungkyunkwan University School of Medicine, 81, Irwon-ro,

Gangnam-gu, Seoul 06351, Republic of Korea

Tel: +82-2-3410-3420 Fax: +82-2-3410-3849

E-mail: yk.on@samsung.com

Copyright (C) 2016 The Official Journal of Korean Heart Rhythm Society Editorial Board and MMK Communications Limited

\begin{abstract}
Background and Objectives: Non-vitamin $\mathrm{K}$ antagonist oral anticoagulants (NOACs) are increasingly used for stroke prevention in patients with non-valvular atrial fibrillation (NVAF), showing better efficacy and safety than warfarin. However, the rates or reasons for discontinuation of NOACs in clinical practice have not been clarified. The aim of this study was to compare 3 NOACs (apixaban, rivaroxaban, and dabigatran) with warfarin in terms of medication persistence.
\end{abstract}

Subjects and Methods: We retrospectively evaluated 1,527 patients with NVAF who had recently started taking NOACs between January 2012 and September 2015 (294 apixaban, 748 rivaroxaban, and 485 dabigatran) and compared them with 363 patients with NVAF who started taking warfarin between January 2012 and December 2013 at the Samsung Medical Center.

Results: The mean follow-up duration was 532 days. The discontinuation rates were higher in the 3 NOAC groups than in the warfarin group within the first year. The major causes of discontinuation were maintenance of sinus rhythm; adverse events, including all bleeding and gastrointestinal symptoms; and patients demand. The adverse event rate was lower in the warfarin group than in the 3 NOAC groups. No significant differences in thromboembolic and major bleeding events were found between the 3 NOAC groups and the warfarin group.

Conclusion: In a single-center study, NOACs showed lower medication persistence and higher adverse event rates than warfarin during the first year.

Key Words: - Atrial Fibrillation -Warfarin -Medication Persistence - Treatment Efficacy - NOAC

\section{Introduction}

Atrial fibrillation (AF) is the most common cardiac arrhythmia in clinical practice. AF is a global health-care problem with an increasing prevalence and incidence. ${ }^{1}$ Patients with $\mathrm{AF}$ are at increased risk of death, heart failure, hospitalization, and 
thromboembolic events. ${ }^{2}$ AF-associated strokes are often severe, resulting in disability or death. ${ }^{3}$ Thus, an oral anticoagulation therapy such as vitamin K-antagonist anticoagulants (VKAs) is important for the prevention of stroke in patients at risk of AF.

Recently, several non-vitamin K-antagonist oral anticoagulants (NOACs) have been introduced. Randomized clinical trials (RCTs) showed that NOACs were superior to VKAs in efficacy and safety of preventing stroke and systemic embolisms in patients with non-valvular AF (NVAF). ${ }^{4-6}$ Current AF guidelines recommend risk stratification and use of NOACs. ${ }^{7}$

NOACs provide lifestyle advantages, and efficacy and safety in stroke prevention. The use of NOACs is gradually increasing worldwide. The aim of this study was to evaluate the medication persistence of NOACs in comparison with that of warfarin.

\section{Subjects and Methods}

\section{Study population and study design}

This is a retrospective study of patients with NVAF who were indicated for AF treatment. We included 1,527 patients with NVAF who had newly started NOAC therapy between January 2012 and September 2015 (294 apixaban cases between March 2014 and September 2015, 748 rivaroxaban cases between July
2012 and September 2015, and 485 dabigatran cases between January 2012 and September 2015) and 363 patients with NVAF who started warfarin therapy between January 2012 and December 2013 at the Samsung Medical Center (Figure 1).

Clinical data were collected from the patients' medical records to identify patients to whom NOACs or warfarin was prescribed, and those diagnosed with AF. We excluded patients with valvular heart disease, such as patients with moderate or severe mitral stenosis, mild rheumatic mitral stenosis, or a history of valvular surgery.

\section{Clinical characteristics and definition of variables}

Information on baseline characteristics such as patient age, sex, risk factor, and underlying disease were collected from medical records and laboratory data. Hypertension was defined as a systolic blood pressure of $\geq 140 \mathrm{mmHg}$, a diastolic blood pressure of $\geq 90 \mathrm{mmHg}$, or a history of treatment for hypertension.

Diabetes mellitus (DM) previously diagnosed by a physician was defined as treatment with hypoglycemic agents or indicated by poor glycemic control (defined as a glycohemoglobin Alc level of $\geq 6.5 \%$ ).

Heart failure was defined in accordance with the American College of Cardiology/American Heart Association criteria.

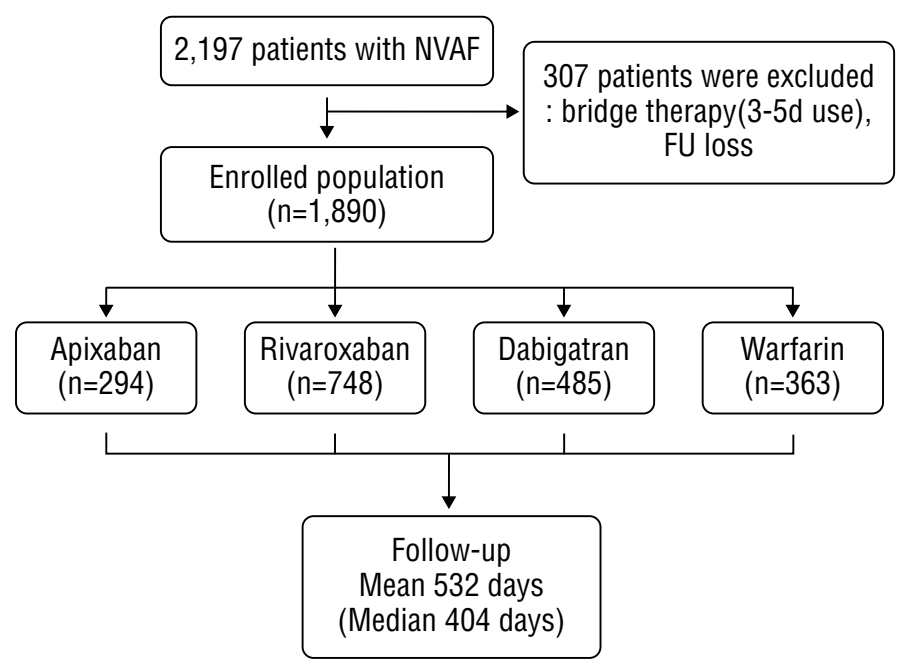

Figure 1. Flow chart of study subjects.

FU, follow-up; NVAF, non-valvular atrial fibrillation 
Creatinine clearance was measured by using the Cockcroft-Gault formula. Coronary artery disease was defined based on positive stress test results, coronary angiograms demonstrating at least $70 \%$ stenosis, coronary spastic angina detected in an ergonovine provocation test or a history of prior myocardial infarction or revascularization procedures.

Non-persistence is defined as not taking prescribed medications, which is different from non-adherence, which is considered when doses are missed, extra doses are taken, or doses are taken in the wrong quantity or at the wrong time. ${ }^{8}$ The terms non-persistence and discontinuation are used interchangeably in this report.

Bleeding includes gastrointestinal bleeding (hematochezia and melena), hematuria, epistaxis, hemoptysis, hematemesis, gingival bleeding, hematoma, and intracranial bleeding. Major bleeding was defined as clinically overt bleeding accompanied by a decrease in hemoglobin level of at least $2 \mathrm{~g} / \mathrm{dL}$ or transfusion of at least 2 units of packed red cells, occurring at a critical site, or resulting in death according to the criteria of the International Society of Thrombosis and Hemostasis. ${ }^{9}$ Minor bleeding was defined as all other clinically overt bleedings that did not meet the criteria for major bleeding and were persistent or recurrent, necessitating contact with the health system for treatment. ${ }^{9}$ Thromboembolic events were defined as documented hospital admission due to acute ischemic stroke/transient ischemic attack (TIA), acute myocardial infarction, or other systemic embolisms.

The $\mathrm{CHA}_{2} \mathrm{DS}_{2}$-VASc score was used to estimate the risk of stroke. The $\mathrm{CHA}_{2} \mathrm{DS}_{2}$-VASc score takes into consideration congestive heart failure/left ventricular ejection fraction of $<40 \%$, hypertension, age of $\geq 75$ years (double), DM, previous diagnosis of stroke/TIA or systemic embolism (double), vascular disease (history of myocardial infarction, peripheral artery), age of 65-75 years, and female sex. Previous bleeding was defined as major or clinically significant bleeding.

The HAS-BLED score was used to estimate the risk of bleeding. The HAS-BLED score takes into consideration hypertension (uncontrolled, $>160 \mathrm{mmHg}$ systolic), abnormal renal and liver functions (dialysis, transplant, Cr level of $\geq 2.26$ / cirrhosis, bilirubin level twice the normal, liver enzyme thrice the normal), stroke, bleeding, labile international normalized ratio (INR), elderly (age >65 years), drugs (antiplatelet and nonsteroidal anti-inflammatory drug), or alcohol.

For apixaban, the standard dose is $5 \mathrm{mg}$ twice daily and the reduced dose is $2.5 \mathrm{mg}$ twice daily. For rivaroxaban, the standard dose is $20 \mathrm{mg}$ once daily and the reduced dose is 15 or $10 \mathrm{mg}$ once daily. For dabigatran, the standard dose is $150 \mathrm{mg}$ twice daily and the reduced dose is $110 \mathrm{mg}$ twice daily.

\section{Follow-up}

Information on drug cessation, major cardiovascular events, and minor adverse events were obtained at routine or additional visits at our hospital. The patients were followed up until the end of the follow-up period or until discontinuation of the drug, loss to follow-up, or death. The follow-up period was until September 2016. Information concerning deceased patients was obtained from medical records, family members, the patients' general practitioners, and the hospitals to which they had been admitted. In the patients who started warfarin, we also collected prothrombin time (PT)-INR data.

\section{Outcomes}

Drug cessation was defined as discontinuation of the prescribed drug and physician's mention of drug cessation in the medical record. All cases of drug cessation were reviewed from the medical records, and the reasons for cessation were also obtained. Temporary discontinuation for specific reasons such as surgery was not considered as drug cessation. Major cardiovascular events are defined as thromboembolism and major bleeding. The occurrence of thromboembolic and bleeding events was evaluated through the medical records reviewed by the 2 investigators.

\section{Statistical analysis}

Summary data are presented either as mean and standard deviation (SD) or as number of patients. Differences in baseline characteristics between NOACs and warfarin were tested with chi-square analysis for categorical variables and analysis of variance for continuous variables. The incidence rates of events were compared between the individual groups by using the chi-square test. The Kaplan-Meier curves for the outcomes of major 
Table 1. Baseline characteristics of patients

\begin{tabular}{|c|c|c|c|c|c|}
\hline & $\begin{array}{c}\text { Apixaban } \\
(\mathrm{n}=294)\end{array}$ & $\begin{array}{c}\text { Rivaroxaban } \\
(\mathrm{n}=748)\end{array}$ & $\begin{array}{c}\text { Dabigatran } \\
(\mathrm{n}=485)\end{array}$ & $\begin{array}{l}\text { Warfarin } \\
(\mathrm{n}=363)\end{array}$ & $P$ value \\
\hline Age (years) & $66 \pm 12$ & $68 \pm 12$ & $68 \pm 11$ & $63 \pm 13$ & $<0.001$ \\
\hline Female & $119(41 \%)$ & $260(35 \%)$ & $145(30 \%)$ & $136(38 \%)$ & 0.015 \\
\hline Body weight (kg) & $66 \pm 12$ & $67 \pm 12$ & $69 \pm 12$ & $68 \pm 12$ & 0.023 \\
\hline Body mass index (kg/m²) & $25 \pm 3$ & $25 \pm 3$ & $25 \pm 3$ & $25 \pm 4$ & 0.149 \\
\hline Heart failure & $62(21 \%)$ & $116(16 \%)$ & $38(8 \%)$ & $64(18 \%)$ & $<0.001$ \\
\hline Diabetes mellitus & $60(20 \%)$ & $167(22 \%)$ & $131(27 \%)$ & $113(31 \%)$ & 0.002 \\
\hline Hypertension & $192(65 \%)$ & $456(61 \%)$ & $319(66 \%)$ & $206(57 \%)$ & 0.031 \\
\hline Chronic kidney disease & $15(5 \%)$ & $16(2 \%)$ & $5(1 \%)$ & $7(2 \%)$ & 0.005 \\
\hline Stroke/TIA & $47(16 \%)$ & $127(17 \%)$ & $69(14 \%)$ & $42(12 \%)$ & 0.109 \\
\hline Coronary artery disease & $59(20 \%)$ & $131(18 \%)$ & $47(10 \%)$ & $37(10 \%)$ & $<0.001$ \\
\hline $\mathrm{CABG} / \mathrm{PCI}$ & $29(10 \%)$ & $75(10 \%)$ & $25(5 \%)$ & $18(5 \%)$ & 0.001 \\
\hline Peripheral vascular disease & $92(31 \%)$ & $62(8 \%)$ & $27(6 \%)$ & $16(4 \%)$ & $<0.001$ \\
\hline Previous bleeding history & $41(14 \%)$ & $38(5 \%)$ & $17(3.5 \%)$ & $5(1.4 \%)$ & $<0.001$ \\
\hline $\mathrm{CHA}_{2} \mathrm{DS}_{2}$-VASc score* & $3.2 \pm 1.8$ & $2.9 \pm 1.8$ & $2.6 \pm 1.7$ & $2.5 \pm 1.7$ & $<0.001$ \\
\hline 0 & $8(3 \%)$ & $86(12 \%)$ & $54(11 \%)$ & $43(12 \%)$ & \\
\hline 1 & $52(18 \%)$ & $92(12 \%)$ & $79(16 \%)$ & $85(23 \%)$ & \\
\hline $2-6$ & $234(79 \%)$ & $570(76 \%)$ & $352(73 \%)$ & $235(65 \%)$ & \\
\hline HAS-BLED score ${ }^{\dagger}$ & $2.2 \pm 1.5$ & $1.7 \pm 1.2$ & $2.0 \pm 1.2$ & $1.1 \pm 0.9$ & $<0.001$ \\
\hline$<3$ & $182(62 \%)$ & $556(74 \%)$ & $331(68 \%)$ & $341(83 \%)$ & \\
\hline$\geq 3$ & $112(38 \%)$ & $192(26 \%)$ & $154(32 \%)$ & $22(17 \%)$ & \\
\hline Dose (mg daily) of NOACs (n, \%) & $\begin{array}{c}10 \mathrm{mg} \\
(190,64.6 \%) \\
5 \mathrm{mg} \\
(104,35.4 \%)\end{array}$ & $\begin{array}{c}20 \mathrm{mg} \\
(418,55.9 \%) \\
15 \mathrm{mg} \\
(300,40.1 \%) \\
10 \mathrm{mg} \\
(30,4 \%)\end{array}$ & $\begin{array}{c}300 \mathrm{mg} \\
(193,39.8 \%) \\
220 \mathrm{mg} \\
(292,60.2 \%)\end{array}$ & & \\
\hline RFCA and TTA & 70 (24\%) & 116 (16\%) & $73(15 \%)$ & $91(25 \%)$ & $<0.001$ \\
\hline
\end{tabular}

The values are presented as mean $\pm \mathrm{SD}$ or number of patients (\%).

${ }^{*} \mathrm{CHA}_{2} \mathrm{DS}_{2}-\mathrm{VASC}=$ congestive heart failure/left ventricular dysfunction, hypertension, age $\geq 75$ years (doubled), diabetes mellitus, previous stroke/TIA (doubled), vascular disease, age 65-75 years, female sex

HHAS-BLED score = hypertension (uncontrolled, $>160 \mathrm{mmHg}$ systolic), abnormal renal and liver function (dialysis, transplant, $\mathrm{Cr} \geq 2.26$ / cirrhosis, bilirubin $>2 x$ normal, liver enzyme $>3 x$ normal), stroke, bleeding, labile INR, elderly (age > 65), drugs (antiplatelet, nonsteroidal anti-inflammatory drug) or alcohol CABG, coronary artery bypass graft; NOACs, non-vitamin K antagonist oral anticoagulants; PCI, percutaneous coronary intervention; RFCA, radiofrequency catheter ablation; TIA, transient ischemic attack; TTA, totally thoracoscopic ablation 

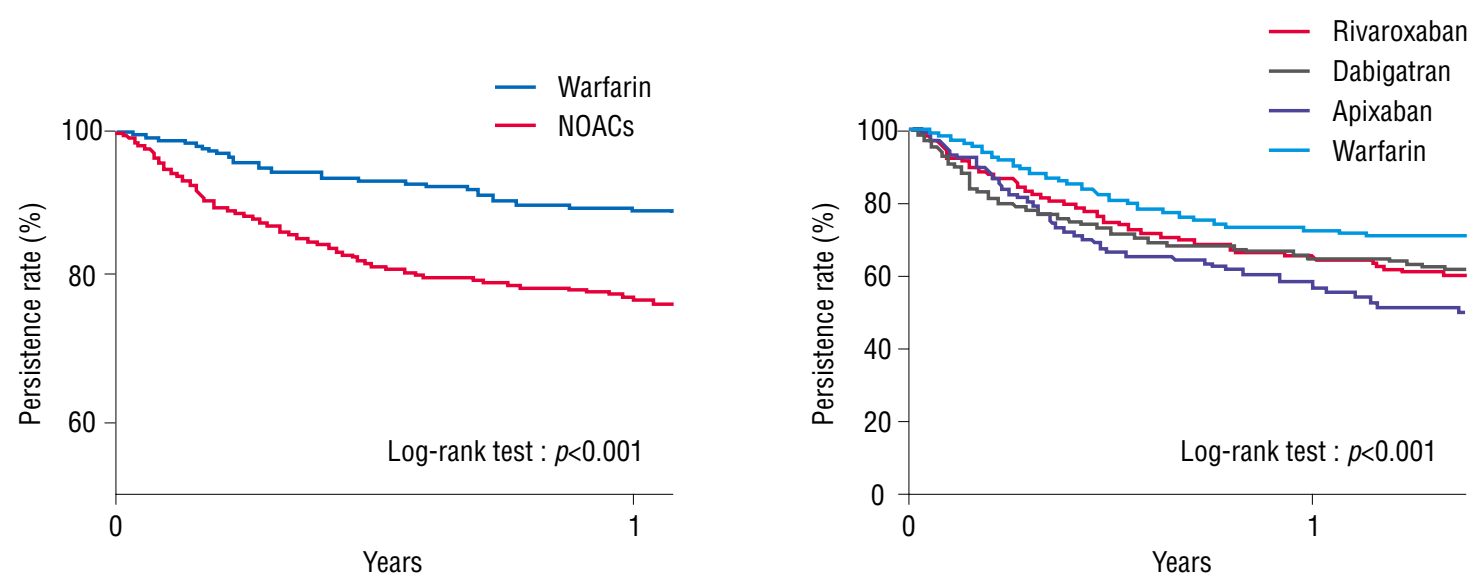

Figure 2. Kaplan-Meier curves for the persistence of NOACs and warfarin NOACs, non-vitamin $\mathrm{K}$ antagonist oral anticoagulants
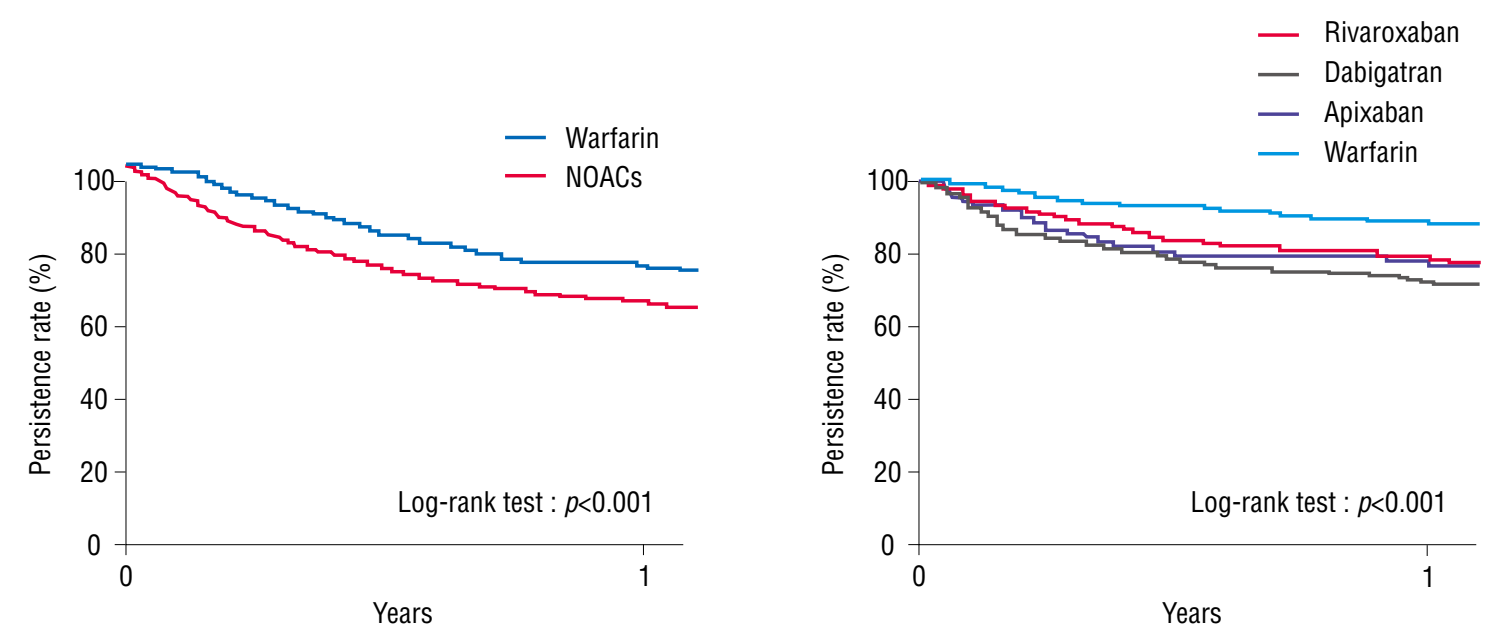

Figure 3. Kaplan-Meier curves for the persistence of NOACs and warfarin except patients with maintenance of sinus rhythm NOACs, non-vitamin $\mathrm{K}$ antagonist oral anticoagulants

cardiovascular events and discontinuation according to the NOACs were created by using the log-rank test. $P$ values of $<0.05$ were considered significant. Data analyses were performed by using the SPSS statistical version 20 software (SPSS Inc., Chicago, Illinois).

\section{Results}

\section{Patient characteristics}

The baseline characteristics of the patients in the 3 NOAC groups and the warfarin group are shown in Table 1. Significant differences in age, sex, body weight, incidences of heart failure, hypertension, DM, chronic kidney disease, peripheral vascular disease, coronary artery disease, coronary artery bypass surgery/ percutaneous coronary intervention, and previous bleeding history were found among the groups. Significant differences in mean $\mathrm{CHA}_{2} \mathrm{DS}_{2}$-VASc and HAS-BLED scores were also found among the groups. 


\section{Discontinuation and persistence of NOACs and warfarin}

The mean follow-up duration was 532 days (median, 404 days). The discontinuation rates and cause of cessation in the 3 NOAC groups and warfarin groups are shown in Table 2. The major causes of discontinuation were maintenance of sinus rhythm; adverse events, including all bleeding and gastrointestinal symptoms; and patient's request. Maintenance of sinus rhythm was the most common reason for discontinuing drugs in all the groups. Most cases of discontinuation on patient request were due to the costs of NOACs that are not covered by medical insurance. Gastrointestinal symptoms were more frequent than bleeding from adverse events in the dabigatran group. Various medical conditions included risk for interaction with concomitant medication, worsened renal function, cancer, and coronary artery intervention. The Kaplan-Meier curve for persistence of NOACs and warfarin are presented in Figure 2. The discontinuation rate in the warfarin group was lower than that in the NOAC groups. We excluded maintenance of sinus rhythm to calculate the persistence rate because many patients discontinued anticoagulation because of maintenance of sinus rhythm by operation or procedure such as radiofrequency ablation (RFCA) or total thoracoscopic ablation (TTA; Table 1). The KaplanMeier curves for persistence of NOACs and warfarin without maintenance of sinus rhythm are shown in Figure 3. The discontinuation rate was higher in all the NOAC groups than in the warfarin group. The incidence rate of adverse events in the warfarin group was lower than those in the 3 NOAC groups within the first year of treatment.

\section{Major cardiovascular events}

The warfarin group had lower mean $\mathrm{CHA}_{2} \mathrm{DS}_{2}$-VASc and HAS-BLED scores than the 3 NOAC groups. No significant differences in the incidence of thromboembolic and major bleeding events were found between the NOAC groups and the warfarin groups (Table 3). The warfarin group tended to have a higher incidence of major bleeding than the 3 NOAC groups, but the difference was not statistically significant.

\section{Antithrombotic treatment after discontinuation}

Antithrombotic treatments after discontinuation are shown in Table 4. The patients who discontinued NOACs mostly received another NOAC or an antiplatelet drug except for the apixaban group. Apixaban group tended not to receive any antithrombotic treatment. The patients who discontinued warfarin also received a NOAC or an antiplatelet drug.

\section{Discussion}

\section{The persistence of NOAC and warfarin}

This study showed the persistence and adverse events related to the administration of the 3 NOACs (apixaban, rivaroxaban, and dabigatran) in comparison with those related to warfarin administration in real-world practice. Only few reports have focused on this issue with respect to Korean patients with NVAF. Our data showed that both the NOAC and warfarin groups had low drug persistence. Approximately four-tenth of patients discontinued the drug in both groups. Medication persistence significantly differed between the NOACs groups and the warfarin group, but not during the total follow-up period in this study. Several aspects of our results should be considered. The follow-up duration in the warfarin group was 2 times longer than that in the NOAC group (435 vs. 943 days). The medication persistence in the NOAC group was lower than that in the warfarin group within the first year. The findings are shown in Figures 2 and 3. Maintenance of sinus rhythm, adverse events, and patient's request were the major causes of drug discontinuation. The proportion of maintenance of sinus rhythm was especially higher than those of other causes. Several patients had sinus conversion by ablation procedures such as RFCA or TTA in both the NOAC and warfarin groups. We evaluated the discontinuation rate without maintenance of sinus rhythm. The persistence in the NOAC group was still lower than that in the warfarin group within the first year after exception of maintenance of sinus rhythm (apixaban/rivaroxaban/dabigatran $=19.7 \% / 21.5 \% / 26.6 \%$ vs. warfarin $=17.4 \%$ ).

The clinical trial of dabigatran in comparison with warfarin showed that the discontinuation rates for $110 \mathrm{mg}$ of dabigatran, $150 \mathrm{mg}$ of dabigatran, and warfarin were, respectively, $14.5 \%$, $15.5 \%$, and $10.2 \%$ at 1 year and $20.7 \%, 21.2 \%$, and $16.6 \%$ at 2 
Table 2. Discontinuation of drug and cause of cessation

\begin{tabular}{|c|c|c|c|c|c|}
\hline & $\begin{array}{l}\text { Apixaban } \\
(\mathrm{n}=294)\end{array}$ & $\begin{array}{l}\text { Rivaroxaban } \\
(\mathrm{n}=748)\end{array}$ & $\begin{array}{l}\text { Dabigatran } \\
(\mathrm{n}=485)\end{array}$ & $\begin{array}{l}\text { Warfarin } \\
(n=363)\end{array}$ & $P$ value \\
\hline Discontinuation & $119(40.5 \%)$ & $283(37.8 \%)$ & $180(37.1 \%)$ & $141(38.8 \%)$ & 0.803 \\
\hline Mean follow-up period & $292 \pm 155$ & $465 \pm 312$ & $472 \pm 357$ & $943 \pm 487$ & \\
\hline \multicolumn{6}{|l|}{ Cause of cessation } \\
\hline Adverse events & $25(8.5 \%)$ & $78(10.4 \%)$ & $69(14.2 \%)$ & $27(7.4 \%)$ & 0.007 \\
\hline Gastrointestinal symptoms or others & $3(1 \%)$ & $9(1.2 \%)$ & $40(8.2 \%)$ & $3(0.8 \%)$ & \\
\hline Bleeding event & $22(7.5 \%)$ & $69(9.2 \%)$ & $29(6.0 \%)$ & $24(6.6 \%)$ & \\
\hline Patient's request & $25(8.5 \%)$ & $68(9.1 \%)$ & $49(10.1 \%)$ & $35(9.6 \%)$ & \\
\hline Maintenance of sinus rhythm & $61(20.7 \%)$ & $122(16.3 \%)$ & $51(10.5 \%)$ & $78(21.5 \%)$ & \\
\hline Various medical conditions ${ }^{\star}$ & $8(2.7 \%)$ & $15(2.0 \%)$ & $11(1.9 \%)$ & $1(0.3 \%)$ & \\
\hline $\begin{array}{l}\text { Discontinuation except patients with } \\
\text { maintenance of sinus rhythm }\end{array}$ & $58(19.7 \%)$ & $161(21.5 \%)$ & $129(26.6 \%)$ & $63(17.4 \%)$ & 0.011 \\
\hline
\end{tabular}

The values are presented as mean $\pm S D$ or number of patients (\%).

*Various medical conditions include risk for interaction with concomitant medication, worsened renal function, cancer, and coronary artery intervention

Table 3. Thromboembolic and major bleeding events

\begin{tabular}{|c|c|c|c|c|c|}
\hline & $\begin{array}{c}\text { Apixaban } \\
(\mathrm{n}=294)\end{array}$ & $\begin{array}{l}\text { Rivaroxaban } \\
(n=748)\end{array}$ & $\begin{array}{c}\text { Dabigatran } \\
(\mathrm{n}=485)\end{array}$ & $\begin{array}{l}\text { Warfarin } \\
(\mathrm{n}=363)\end{array}$ & $P$ value \\
\hline $\mathrm{CHA}_{2} \mathrm{DS}_{2}$-VASc score* & $3.2 \pm 1.8$ & $2.9 \pm 1.8$ & $2.6 \pm 1.7$ & $2.5 \pm 1.7$ & $<0.001$ \\
\hline HAS-BLED score & $2.2 \pm 1.5$ & $1.7 \pm 1.2$ & $2.0 \pm 1.2$ & $1.1 \pm 0.9$ & $<0.001$ \\
\hline Mean follow-up period & $292 \pm 155$ & $465 \pm 312$ & $472 \pm 357$ & $943 \pm 487$ & \\
\hline Thromboembolism & $3(1.25 \% / y r)$ & $8(0.86 \% / y r)$ & $6(0.93 \% / y r)$ & $7(0.74 \% / y r)$ & 0.649 \\
\hline Ischemic stroke & 3 & 4 & 6 & 5 & \\
\hline TIA & 0 & 2 & 0 & 0 & \\
\hline Systemic embolism & 0 & 2 & 0 & 2 & \\
\hline Major bleeding & $3(1.25 \% / y r)$ & $12(1.26 \% / y r)$ & $2(0.31 \% / y r)$ & $13(1.39 \% / y r)$ & 0.142 \\
\hline Intracranial hemorrhage & 0 & 7 & 0 & 2 & \\
\hline Gastrointestinal bleeding & 2 & 3 & 2 & 6 & \\
\hline Others & 1 & 2 & 0 & 5 & \\
\hline
\end{tabular}

The values are presented as mean \pm SD or number of patients (\%/year).

${ }^{*} \mathrm{CHA}_{2} \mathrm{DS}_{2}$-VASC = congestive heart failure/left ventricular dysfunction, hypertension, age $\geq 75$ years (doubled), diabetes mellitus, previous stroke/TIA (doubled), vascular disease, age 65-75 years, female sex

TIA, transient ischemic attack 
Table 4. Antithrombotic treatment after discontinuation

\begin{tabular}{lcccc}
\hline & $\begin{array}{c}\text { Apixaban } \\
(\mathrm{n}=119)\end{array}$ & $\begin{array}{c}\text { Rivaroxaban } \\
(\mathrm{n}=283)\end{array}$ & $\begin{array}{c}\text { Dabigatran } \\
(\mathrm{n}=180)\end{array}$ & $\begin{array}{c}\text { Warfarin } \\
(\mathrm{n}=141)\end{array}$ \\
\hline Warfarin & $9(7.6 \%)$ & $33(11.7 \%)$ & $28(15.6 \%)$ & $8(5.7 \%)$ \\
NOACs & $19(20.0 \%)$ & $70(24.7 \%)$ & $70(38.9 \%)$ & $56(39.7 \%)$ \\
$\quad$ Apixaban & 12 & 24 & 14 & 19 \\
$\quad$ Rivaroxaban & 7 & 45 & 32 & 22 \\
Dabigatran & 0 & 1 & 24 & 11 \\
Edoxaban & - & - & - & 4 \\
Antiplatelet agent* & $35(29.4 \%)$ & $97(34.3 \%)$ & $64(35.6 \%)$ & $60(42.6 \%)$ \\
None & $56(47.1 \%)$ & $83(29.3 \%)$ & $18(10 \%)$ & $17(12.0 \%)$ \\
Previous drug maintenance & $12(10.1 \%)$ & $45(15.9 \%)$ & $24(13.3 \%)$ & $8(5.7 \%)$ \\
\hline
\end{tabular}

The values are presented as mean $\pm S D$ or number of patients (\%).

NOACs, non-vitamin $\mathrm{K}$ antagonist oral anticoagulants

${ }^{*}$ Antiplatelet agent $=$ aspirin or $\mathrm{P}_{2} \mathrm{Y}_{12}$ receptor antagonist

years. ${ }^{4}$ The clinical trial of apixaban in comparison with warfarin showed that fewer patients (25.3\%) in the apixaban group than in the warfarin group $(27.5 \%)$ discontinued a study drug before the end of the study. ${ }^{5}$ The clinical trial of rivaroxaban in comparison with warfarin showed that the proportion of patients who discontinued their assigned drug was $23.7 \%$ in the rivaroxaban group and $22.2 \%$ in the warfarin group. ${ }^{6}$ The discontinuation rates for the NOACs in the major clinical trials ranged from $21-25 \%$. The major clinical trials ${ }^{46}$ showed that the persistence rates in the dabigatran and rivaroxaban groups were lower than that in the warfarin group, and that the persistence rate in the apixaban group was similar to that of warfarin group. Our study finding on the persistence of anticoagulation drugs is consistent with the results of the RE-LY, ROCKET-AF, and ARISTOTLE trials. The reason of the better persistence of warfarin in this study is not clearly defined, but differences in tolerability may have contributed. The necessity of close monitoring by PT-INR in the warfarin group might be its better persistence. The incidence of adverse events was also lower in the warfarin group as was the persistence rate. The selection bias or lower $\mathrm{CHA}_{2} \mathrm{DS}_{2}$-VASc and HAS-BLED scores in the warfarin group could explain these findings. Several studies in clinical practice show that the warfarin group had better persistence than the NOAC group. A retrospective study by Tsuyoshi et $a .^{10}$ reported that the persistence in Japanese patients with NVAF who received NOACs was lower than that in patients who received warfarin at 12 months (70\% vs. $82 \%$ ) The study that compared among warfarin $(n=9,969)$, apixaban $(n=1,352)$, rivaroxaban $(n=2,074)$, dabigatran $(n=2,701)$, and aspirin $(n=4,540)$ showed that the persistence rates of all the anticoagulant treatments were high in patients with NVAF after 2-year follow-up (82.9\%) and better persistence of warfarin (85\%) and apixaban (85.9\%) than dabigatran $(74.4 \%)$ or rivaroxaban $(77.4 \%)$ in clinical practice. ${ }^{11}$ These findings are similar to those of our study.

\section{Reasons of cessation and Major complication}

In this study, the major causes of discontinuation were the adverse events or patient's request. Patient's request in major clinical trials accounted for $8-10 \%$ of the total treated population. This finding was similar in our study. The adverse events were not severe, and the minor bleeding or gastrointestinal symptoms were the major reasons. Minor bleeding does not lead to severe major bleeding. Compared with the other NOAC groups and the 
warfarin group, the dabigatran group showed a higher proportion of patients with gastrointestinal symptoms than those with bleeding due to adverse events. The incidence rates of thromboembolic and major bleeding events were not significantly different between the NOAC groups and the warfarin group in clinical practice. These results were lower than those of the major clinical trials. ${ }^{4-6}$ However, these findings should be explained cautiously because this study was retrospective.

\section{Difference of the drug approval time}

The drug approval times of NOACs differ in South Korea. Dabigatran was first approved, which was followed by the approval of rivaroxaban and then apixaban. At the time NOACs were approved, its safety and effectiveness in the clinical real world was not clarified. Concerns have been raised regarding the potential risk of serious adverse events induced by NOACs in comparison with warfarin. Therefore, the discontinuation rates of dabigatran might be higher than that of rivaroxaban or apixaban. As apixaban is the most recently approved drug, the number of patients that can be evaluated is smaller than that of other NOACs.

\section{Persistence to NOAC treatment}

The effectiveness and safety of NOACs were identified continuously by recent studies. The clinical outcomes of AF, such as mortality, stroke, and cardiovascular events, are strongly dependent on the quality of anticoagulation. Although NOACs were more convenient than warfarin as it does not require regular laboratory examination such as PT-INR and lifestyle advantage, it could decrease patient's attention to disease. The patient-physician relationship is important for better adherence. Physicians should provide sufficient information and explain the risk of discontinuation, and the necessity of consultation before drug discontinuation.

\section{Limitations}

This study has several limitations. This study was a retrospective observational study in a single center. We could not detect all minor events due to dependence on medical records. The results of this study might not reflect the situation in the average patient population in South Korea. The follow-up duration was relatively short. The starting points and follow-up period differed between the NOAC and warfarin groups because of the differences in drug-approved times.

\section{Conclusion}

In this study of AF patients, NOACs showed lower persistence rate than warfarin.

\section{Disclosures}

None

\section{Conflict of interest}

The authors report no relationships that could be construed as a conflict of interest.

\section{Acknowledgements}

None

\section{References}

1) Chugh SS, Havmoeller R, Narayanan $K$, Singh D, Rienstra $M$, Benjamin EJ, Gillum RF, Kim YH, McAnulty JH Jr, Zheng ZJ, Forouzanfar MH, Naghavi M, Mensah GA, Ezzati M, Murray CJ. Worldwide epidemiology of atrial fibrillation: a Global Burden of Disease 2010 Study. Circulation. 2014;129:837-847.

2) Chugh SS, Blackshear JL, Shen WK, Hammill SC, Gersh BJ. Epidemiology and natural history of atrial fibrillation: clinical implications. J Am Coll Cardiol. 2001;37:371-378.

3) Wolf PA, Abbott RD, Kannel WB. Atrial fibrillation as an independent risk factor for stroke: the Framingham Study. Stroke. 1991;22:983-988.

4) Connolly SJ, Ezekowitz MD, Yusuf S, Eikelboom J, Oldgren J, Parekh A, Pogue J, Reilly PA, Themeles E, Varrone J, Wang S, Alings M, Xavier D, Zhu J, Diaz R, Lewis BS, Darius H, Diener 
HC, Joyner CD, Wallentin L. Dabigatran versus warfarin in patients with atrial fibrillation. NEngl J Med. 2009;361:1139-1151.

5) Granger CB, Alexander JH, McMurray JJ, Lopes RD, Hylek EM, Hanna M, Al-Khalidi HR, Ansell J, Atar D, Avezum A, Bahit MC, Diaz R, Easton JD, Ezekowitz JA, Flaker G, Garcia D, Geraldes M, Gersh BJ, Golitsyn S, Goto S, Hermosillo AG, Hohnloser SH, Horowitz J, Mohan P, Jansky P, Lewis BS, Lopez-Sendon JL, Pais P, Parkhomenko A, Verheugt FW, Zhu J, Wallentin L. Apixaban versus warfarin in patients with atrial fibrillation. $N$ Engl J Med. 2011;365:981-992.

6) Patel MR, Mahaffey KW, Garg J, Pan G, Singer DE, Hacke W, Breithardt G, Halperin JL, Hankey GJ, Piccini JP, Becker RC, Nessel CC, Paolini JF, Berkowitz SD, Fox KA, Califf RM. Rivaroxaban versus warfarin in nonvalvular atrial fibrillation. $N$ Engl J Med. 2011;365:883-891.

7) January CT, Wann LS, Alpert JS, Calkins H, Cigarroa JE, Cleveland JC, Conti JB, Ellinor PT, Ezekowitz MD, Field ME, Murray KT, Sacco RL, Stevenson WG, Tchou PJ, Tracy CM, Tancy
CW. 2014 AHA/ACC/HRS guideline for the management of patients with atrial fibrillation: a report of the American College of Cardiology/American Heart Association task force on practice guidelines and the Heart Rhythm Society. J Am Coll Cardiol. 2014;64:e1-e76.

8) Ruddy K, Mayer E, Partridge A. Patient adherence and persistence with oral anticancer treatment. Cancer J Clin. 2009;59:56-66.

9) Schulman S, Kearon C. Definition of major bleeding in clinical investigations of antihemostatic medicinal products in non-surgical patients. J Thromb Haemost. 2005;3:692-694.

10) Shiga T, Naganuma M, Nagao T, Maruyama K, Suzuki A, Murasaki K, Hagiwara N. Persistence of non-vitamin K antagonist oral anticoagulant use in Japanese patients with atrial fibrillation: A single-center observational study. J Arrhythm. 2015;31:339-344.

11) Forslund T, Wettermark B, Hjemdahl P. Comparison of treatment persistence with different oral anticoagulants in patients with atrial fibrillation. Eur J Clin Pharmacol. 2016;72:329-338. 